\title{
Subpleural versus Deep Lung Biopsies Obtained during Pleuroscopy for Histological Examination: An Experimental Animal Study
}

\author{
Raef H. Emam ${ }^{a}$ Marios E. Froudarakis ${ }^{d}$ Ahmed I. Refaat ${ }^{b}$ Maha Akl \\ Fabien Maldonado ${ }^{f}$ Philippe Astould, e \\ ${ }^{a}$ Department of Chest Diseases, Cairo University, and Departments of ${ }^{b}$ Anesthesiology and ${ }^{C}$ Pathology, Theodore \\ Bilharz Research Institute, Cairo, Egypt; ${ }^{\mathrm{d} D e p a r t m e n t}$ of Thoracic Oncology, Pleural Diseases, and Interventional \\ Pulmonology, Hôpital Nord, and ' School of Medicine, University of the Mediterranean, Marseille, France; \\ fDivision of Pulmonary and Critical Care Medicine, Mayo Clinic, Rochester, Minn., USA
}

\section{Key Words}

Thoracoscopy $\cdot$ Pleuroscopy $\cdot$ Lung biopsy $\cdot$ Animal

\begin{abstract}
Background: Lung biopsies obtained during medical pleuroscopy using coagulating forceps could represent a costeffective alternative to surgical lung biopsies in patients with diffuse parenchymal lung diseases (DPLD). However, it is not clear whether these patients should undergo deeplung biopsies rather than more superficial subpleural lung biopsies. Objectives: The aim of this experimental animal study was to compare gross and microscopic features of deep and subpleural pleuroscopic lung biopsy samples. Methods: Six male sheep (median weight $40 \mathrm{~kg}$ ) underwent lung biopsies via pleuroscopy under general anesthesia. The following parameters were studied: weight, size, quality of the parenchyma and visceral pleura, parenchymal vessels and bronchial tissue. Results: The mean number of biopsies taken per animal was $4.5 \pm 1.22$ and $4.83 \pm 1.33(p=0.36)$ for deep and subpleural biopsies, respectively. The mean size of deep and subpleural biopsies was $1.758 \pm 0.478$ and $1.283 \pm 0.851$ $\mathrm{cm}^{2}$, respectively $(\mathrm{p}=0.0006)$. The mean weight of deep biopsies and subpleural biopsies was $0.156 \pm 0.092$ and 0.145 $\pm 0.047 \mathrm{mg}$, respectively $(p=0.83)$. No statistically significant difference was found between subpleural and deep bi-
\end{abstract}

opsies regarding the mean quality scores of parenchymapleura $(p=0.36)$, vessels $(p=0.36)$, or bronchial tissue $(p=$ 0.20 ). Conclusion: Both subpleural biopsies obtained during pleuroscopy and deep lung biopsy specimens obtained by electrocautery in animal subjects provided satisfactory material for histologic examination. Therefore, in DPLD, where the subpleural layers are involved, subpleural biopsies obtained during pleuroscopy might be sufficient for establishing an accurate diagnosis.

Copyright $\odot 2012$ S. Karger AG, Basel

\section{Introduction}

Pleuroscopy, performed by pulmonologists, under local anesthesia or conscious sedation, is currently the gold standard for investigating diseases of the pleura $[1,2]$. Pleural biopsies obtained during pleuroscopy have a greater diagnostic yield than closed pleural biopsies, particularly in case of malignant pleural effusions, inasmuch as they enable direct detection of abnormalities of the parietal pleura, thus decreasing the risk of sampling errors. In addition, such biopsies allow one to take larger samples, thus improving the diagnostic yield [2]. Medical thoracoscopy has been used to obtain lung biopsies for the diagnosis of lung diseases with a reported diagnostic accuracy of

\section{KARGER}

Fax +4161306 1234

E-Mail karger@karger.ch

www.karger.com
(C) $2012 \mathrm{~S}$. Karger AG, Basel

0025-7931/12/0845-0423\$38.00/0

Accessible online at:

www.karger.com/res
Marios E. Froudarakis, $\mathrm{MD}, \mathrm{PhD}$

Department of Thoracic Oncology, Pleural Diseases, and Interventional Pulmonology CHU Nord, Chemin des Bourrely

FR-13326 Marseille Cedex 20 (France)

E-Mailmfroud@med.duth.gr 
$75-93 \%$. Yet the technique is not routinely used and few studies have been published in the literature $[3,4]$.

Surgical lung biopsies (usually via video-assisted thoracoscopic surgery, VATS), performed under general anesthesia, remain the standard of care for the definitive diagnosis of parenchymal lesions, especially in patients with diffuse parenchymal lung disease (DPLD), when a combination of clinical, radiologic and bronchoscopic methods fails to provide a clear diagnosis. Lung biopsies obtained via VATS are virtually identical to those obtained by thoracotomy [5]. However, multiple incisions, costly single-use instruments and general anesthesia with single-lung ventilation are required. Moreover, a conversion from thoracoscopy to mini-thoracotomy is not uncommon because of technical difficulties (deep lung biopsies) and/or complications such as prolonged air leak and/or bronchopleural fistula in case of deep lung biopsies [6]. While surgical lung biopsies are still recommended for the definitive diagnosis of DPLD of unclear etiology, particularly when a diagnosis of idiopathic pulmonary fibrosis is entertained, the risks are substantial $[7,8]$. Potential contributing factors include risks of volume-induced injury during single-lung ventilation, aspiration in the perioperative period and postoperative complications (atelectasis or nosocomial pneumonia) [9] Thus, surgical lung biopsies, even via VATS in ambulatory patients, are not an entirely benign procedure [10]. Furthermore, it seems that the site, size and laterality of surgical lung biopsies in patients with DPLD may not have a definite influence on the diagnosis as long as several lobes are sampled [11].

Consequently, it is possible that lung biopsies obtained during pleuroscopy, under conscious sedation with a spontaneously breathing patient, may avoid some of the complications observed with surgical techniques, and prove a cost-effective and safe strategy in the diagnostic management of patients with DPLD [12]. The depth of lung biopsies obtained via coagulation forceps during pleuroscopy needed to provide adequate sampling of the lung parenchyma has not been studied.

In this animal study, we aimed to assess the quality of biopsies obtained during medical pleuroscopy by comparing gross and microscopic features of deep lung biopsies versus more superficial, subpleural lung biopsies.

\section{Methods}

Animals

This study was conducted at the Learning Resource Center, Faculty of Medicine, Cairo University (Egypt), after approval by the Animal Ethics Committee of the National Research Center and the institutional review board. Pleuroscopy was performed in 6 male sheep with a median weight of $40 \mathrm{~kg}$ (range 35-45). The sheep fasted for $24 \mathrm{~h}$ before the procedure. The ear was shaved for intravenous access. Sedation was given by intramuscular injection of ketamine $5 \mathrm{mg} / \mathrm{kg}$ and atropine $0.02 \mathrm{mg} / \mathrm{kg}$ [13]. Fifteen minutes after the injection, the sheep were brought to the operating room where intravenous access was established by a 22 -gauge intravenous cannula in one of the superficial veins of the ear. Intravenous infusion of $0.9 \%$ sodium chloride or lactated Ringer was started. All animals were under cardiorespiratory monitoring. Anesthesia was induced by intravenous sodium thiopental 2-4 $\mathrm{mg} / \mathrm{kg}$ (sleep dose) and atracurium $0.5 \mathrm{mg} / \mathrm{kg}$ was administered [14]. The animals were ventilated with isoflurane $1.5 \%$ in $100 \%$ oxygen for $3 \mathrm{~min}$ then using the straight blade laryngoscope size 4 (Miller blade size 4), a cuffed endotracheal tube (internal diameter $8.5 \mathrm{~mm}$ ) was inserted. Placement of the tube was confirmed by auscultation, capnography and fiberoptic bronchoscopy. The animal was connected to a ventilator with controlled mechanical ventilation: respiratory rate $16 / \mathrm{min}$, tidal volume $10 \mathrm{ml} /$ $\mathrm{kg}$, I:E ratio $1: 2$ and peak airway pressure was kept under 30 $\mathrm{mm} \mathrm{Hg}$.

After the end of the procedure, the animals were sacrificed using 2 ampoules of potassium chloride $(\mathrm{KCl})$ injected intravenously, and cessation of heart beats was confirmed.

\section{Pleuroscopic Procedure in Animals}

The tidal volume was reduced to $6 \mathrm{ml} / \mathrm{kg}$ to enable the pulmonologists to perform the procedure. A pneumothorax was induced by the introduction of about $200 \mathrm{ml}$ of air into the pleural space through a smooth-ended pleural needle under pleural pressure control. After local anesthesia with $2 \%$ lidocaine, a $10-\mathrm{mm}$ incision in the 4 th or 5 th intercostal space on the mid-axillary line was made. After blunt dissection of the intercostal space, a 7-mm trocar (Karl Storz, Germany) was inserted. The pleural cavity was explored using a 6-mm telescope (Karl Storz) and the appearance of the lung surface carefully inspected. Cup biopsy forceps (Karl Storz) were passed through a second 5-mm insulated trocar (Karl Storz). The cup biopsy forceps were dipped into the lung parenchyma in an open position, then they were closed and a lung sample was taken while applying short pulses of diathermy coagulation. Five deep biopsies (with the forceps cup completely dipped into the lung parenchyma) and another 5 more superficial subpleural ones were taken from each sheep. A subpleural biopsy was defined as a biopsy with only half of the forceps cup dipped into the lung parenchyma.

The biopsies were immediately fixed in $10 \%$ formalin. Overall, 10 lung biopsies ( 5 subpleural and 5 deep biopsies) were obtained from each animal

\section{Histopathology}

Subpleural and deep biopsies were weighed and subjected to detailed gross examination. The specimens were then embedded in paraffin blocks. Four-micrometer-thick sections (2 sections from each specimen) were cut from each specimen with a microtome. One was stained with hematoxylin and eosin and the other with Masson trichrome. Sections were examined by an independent pathologist under a light microscope to identify and compare histological features between the two biopsies; the pathologist was blinded to the biopsy procedure. 
Table 1. Results of the pathologic examination of all deep and subpleural biopsies

\begin{tabular}{|c|c|c|c|c|c|c|c|c|c|c|c|c|}
\hline Sheep & $\mathrm{n}$ & $\begin{array}{l}\text { weight } \\
\text { mg }\end{array}$ & $\begin{array}{l}\text { size } \\
\mathrm{cm}^{2}\end{array}$ & $\begin{array}{l}\text { quality of } \\
\text { parenchy- } \\
\text { ma-pleura }\end{array}$ & $\begin{array}{l}\text { quality } \\
\text { of } \\
\text { vessels }\end{array}$ & $\begin{array}{l}\text { quality of } \\
\text { bronchial } \\
\text { tissue }\end{array}$ & $\mathrm{n}$ & $\begin{array}{l}\text { weight } \\
\mathrm{mg}\end{array}$ & $\begin{array}{l}\text { size } \\
\mathrm{cm}^{2}\end{array}$ & $\begin{array}{l}\text { quality of } \\
\text { parenchy- } \\
\text { ma-pleura }\end{array}$ & $\begin{array}{l}\text { quality } \\
\text { of } \\
\text { vessels }\end{array}$ & $\begin{array}{l}\text { quality of } \\
\text { bronchial } \\
\text { tissue }\end{array}$ \\
\hline 1 & 4 & 0.1 & 0.75 & 2 & 3 & 3 & 3 & 0.2 & 0.28 & 3 & 2 & 3 \\
\hline 2 & 4 & 0.34 & 2 & 4 & 2 & 3 & 5 & 0.1 & 1.5 & 4 & 2 & 2 \\
\hline 5 & 4 & 0.09 & 2 & 4 & 2 & 3 & 4 & 0.2 & 1.4 & 4 & 2 & 2 \\
\hline 6 & 4 & 0.15 & 1.8 & 4 & 2 & 3 & 5 & 0.09 & 1.28 & 4 & 2 & 2 \\
\hline Mean & 4.5 & 0.156 & $1.758^{*}$ & 3.66 & 2.16 & 2.83 & 4.83 & 0.145 & $1.283^{*}$ & 3.83 & 2 & 2.33 \\
\hline SD & 1.22 & 0.0926 & 0.748 & 0.816 & 0.408 & 0.408 & 1.33 & 0.047 & 0.851 & 0.408 & 0 & 0.471 \\
\hline
\end{tabular}

${ }^{*} \mathrm{p}=0.0006$.

The following parameters were studied in both groups (deep lung and subpleural biopsies): number of specimens taken, weight and size of the specimen, quality of parenchyma, visceral pleura, parenchymal vessels and bronchial tissue. The quality of the biopsy for each qualitative parameter was scored according to the following scale [3]: $0=$ no finding, $1=$ poor quality, $2=$ average quality, 3 = good quality, 4 = excellent quality. The total score for each parameter studied for an animal was then calculated; this score was divided by the number of biopsies to obtain the average score.

\section{Statistical Analysis}

Statistics were performed using StatView software. Student's t test was used to compare differences between means of the studied parameters. The differences were considered significant for $\mathrm{p}<0.05$ (two-tailed).

\section{Results}

A total of 54 lung biopsies were obtained from 6 animals: 27 deep and 27 subpleural lung biopsies. No significant bleeding at the site of biopsy was noted in any animal for either technique. The mean number of biopsies taken per animal was $4.5 \pm 1.22$ and $4.83 \pm 1.33$ for deep and subpleural lung biopsies, respectively; the difference is not statistically significant $(\mathrm{p}=0.36)$. At least one representative section was analyzed from each biopsy.

\section{Histopathology}

Biopsy Size and Weight

The size of deep biopsies ranged from 1.12 to $2.88 \mathrm{~cm}^{2}$ while that of subpleural biopsies ranged from 0.28 to 2.7 $\mathrm{cm}^{2}$. The mean size was $1.758 \pm 0.478$ and $1.283 \pm 0.851$ $\mathrm{cm}^{2}$ for deep and subpleural biopsies, respectively. This difference is statistically significant $(\mathrm{p}<0.001)$. The weight of deep biopsies ranged from 0.09 to $0.34 \mathrm{mg}$ while that of subpleural biopsies ranged from 0.09 to $0.2 \mathrm{mg}$. The mean weight for deep biopsies was $0.156 \pm 0.092 \mathrm{mg}$ and that of subpleural biopsies was $0.145 \pm 0.047 \mathrm{mg}$. This difference is not statistically significant $(\mathrm{p}=0.83)$.

\section{Qualitative Results}

The scores of histopathological qualitative parameters (parenchyma, pleura, vessels and bronchial tissue) are shown in table 1 . The mean quality scores for parenchyma-pleura ( $p=0.36)$, vessel $(p=0.36)$, or bronchial tissue $(\mathrm{p}=0.20)$ did not statistically significantly differ between subpleural and deep biopsies. No significant artifacts were seen in both deep or subpleural biopsies. Small, focal areas of crush and thermal artifacts identified on the perimeter of some forceps biopsy specimens did not affect the overall histological interpretability. Low-magnification views of subpleural and deep biopsies are shown in figures $1 \mathrm{a}, \mathrm{b}$ and $2 \mathrm{a}, \mathrm{b}$, respectively.

\section{Discussion}

Biopsies using coagulating forceps, allowing the pulmonologist to obtain at once lung biopsy samples and adequate lung hemostasis and aerostasis, were performed in sheep. Our experimental series showed that subpleural biopsies presented the same histological characteristics as deep lung biopsies. Although we did not attempt to address the technical difficulties or potential complications of either technique, no significant bleeding was noted 
Fig. 1. a Superficial thoracoscopic biopsy showing a wide background of pulmonary tissue, bronchiolar tissue (right arrow) and blood vessels (two left arrows). Hematoxylin and eosin. $\times 100$. b Superficial thoracoscopic biopsy showing a wide background of pulmonary tissue (upper right arrow), bronchiolar tissue (lower right arrow) and blood vessels (left arrow). Masson trichrome. $\times 100$.

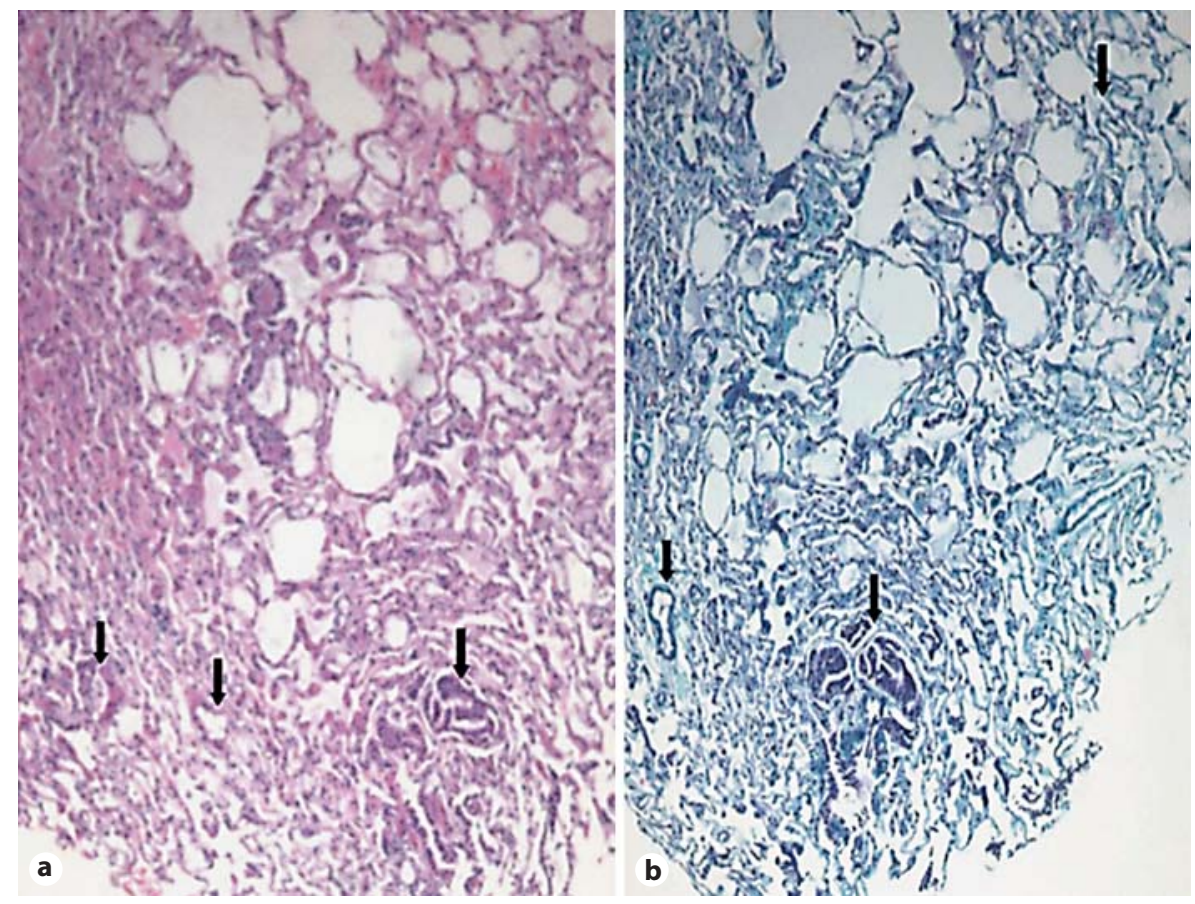

and lung biopsy artifacts due to electrocautery were acceptable with both techniques.

Despite encouraging results published in the literature, reporting a high diagnostic yield of thoracoscopy in patients with diffuse lung disease using electrocautery lung biopsy $[3,15]$, most pulmonologists do not use this technique in the diagnostic workup of DPLD. Furthermore, experimental studies showed that multiple small (less than $5 \mathrm{~mm}$ ) electrocautery lung biopsies were of comparable quality compared with single-wedge biopsy specimens obtained by endoscopic sampling [16]. However, many pulmonologists probably still fear the use (and the complications) of pleuroscopy in the diagnosis of lung parenchyma lesions while many pathologists still have to become acquainted with the smaller amount of tissue compared with the larger surgical samples [3]. Our study suggests that subpleural lung biopsies obtained with coagulation forceps during medical thoracoscopy are feasible and may provide adequate sampling of the lung parenchyma. While this technique clearly has no role in the assessment of deep or peripheral localized lesions, subpleural lung biopsies obtained during pleuroscopy may prove a valuable alternative to surgical lung biopsies in the diagnostic management of DPLD [15].

In about $70 \%$ of the cases, an accurate diagnosis of DPLD is established on the basis of a consistent clinical history, suggestive high-resolution chest computed to- mography (HRCT) images $[17,18]$ and, occasionally, by supportive information provided by bronchoalveolar lavage, transbronchial biopsy $[19,20]$ or transbronchial needle aspiration in case of mediastinal adenopathies [18]. This approach is usually sufficient in patients with pulmonary parenchymal infection, lung fibrosis, sarcoidosis, lymphangitis carcinomatosa, hypersensitivity pneumonitis, amyloidosis, Langerhans cell histiocytosis, eosinophilic pneumonia, alveolar proteinosis, or lymphangioleiomyomatosis. Lung tissue is still required for the diagnosis of DPLD in approximately $30 \%$ of patients who do not have a clearly defined environmental exposure or obvious systemic illness with lung manifestations. The decision to perform a lung biopsy in these patients is based on the likelihood that the pathologic examination of the tissue obtained will yield specific information about the cause of the disease process and that this information can be used to alter the patient's treatment [21]. The diagnostic accuracy of specimens for DPLD depends on the distribution pattern of the interstitial disease, the lobular compartment involved and the histological features of the disease [22, 23]. It is well known that DPLD does not have a uniform spread throughout the whole lung [21]. Pleuroscopy gives the unique opportunity to inspect the whole lung, choose the biopsy areas carefully and take biopsies from several lobes. However, in patients with fibrotic lungs, biopsies 
Fig. 2. a Deep thoracoscopic biopsy showing a background of pulmonary tissue, scattered bronchiolar tissue (white arrows) and blood vessels (black arrow). Hematoxylin and eosin. $\times 100$. b Deep thoracoscopic biopsy showing a background of pulmonary tissue, mostly compressed lung alveoli at the top, a large amount of bronchiolar tissue (white arrows) and blood vessels (black arrows). Masson trichrome. $\times 100$.
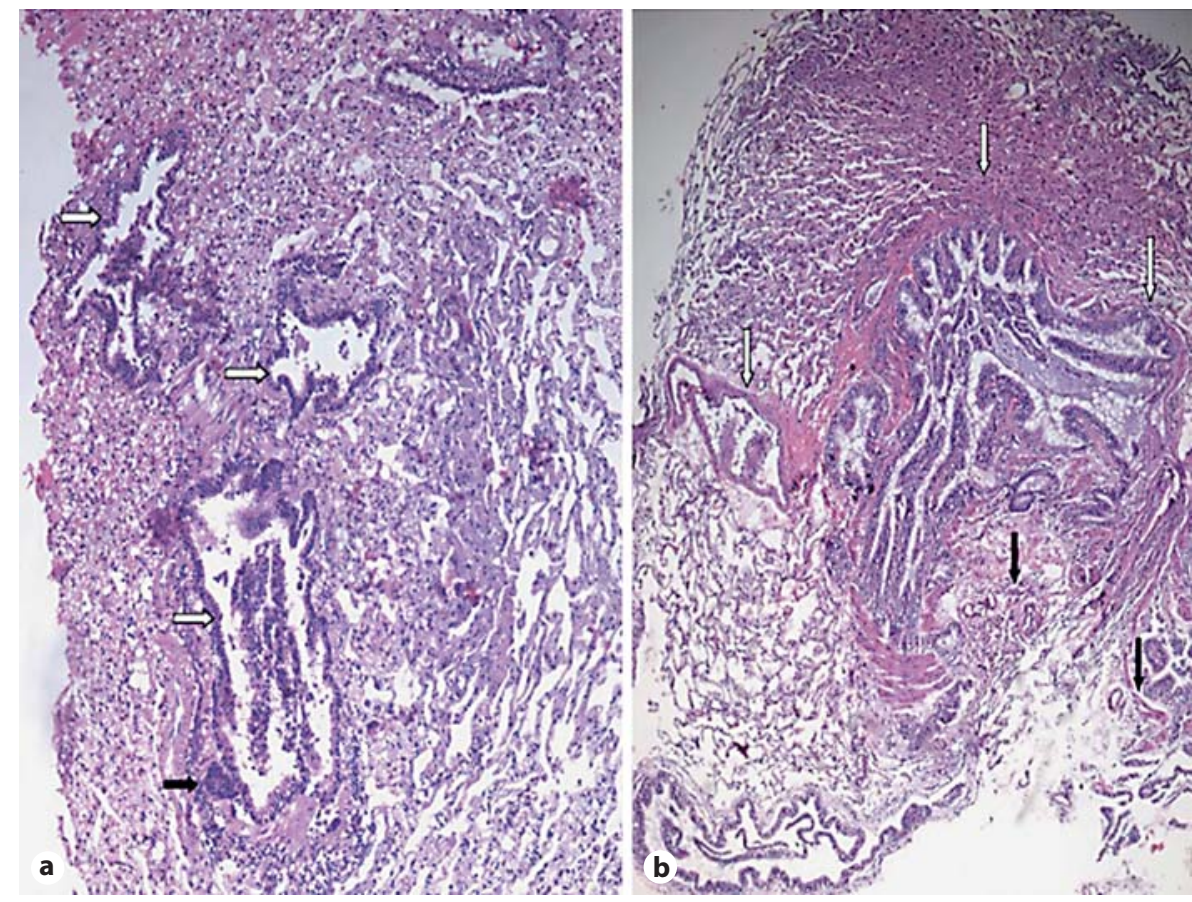

taken from areas with honeycombing are seldom informative, as the findings might be common to a variety of lung parenchyma disorders, irrespective of underlying etiology [24]. At the same time, biopsying fibrotic areas might expose the patient to prolonged air leak with significant impact on the hospital stay due to prolonged drainage $[21,24]$. Besides, given the high diagnostic accuracy of HRCT in the recognition of fibrotic patterns, especially usual interstitial pneumonia (UIP), a lung biopsy is not necessary for diagnosis [17, 19, 20, 25]. Also, in a clinical context in which the diagnosis of UIP can be obtained as a dynamic process that includes an integrated clinical, radiological and pathologic approach, a reliable diagnosis of UIP can be obtained based on a typical definite HRCT with no risk of including patients with a more benign disease and a longer survival [26].

Adequate samples of pleural tissue, interlobular septa and alveolated parenchyma were obtained in all subpleural biopsies in our study. DPLD with preferential localization to peripheral areas of the lung can be adequately sampled by this technique. These diseases are characterized by widespread involvement particularly of the alveolar compartment $[22,23]$. In the same spectrum of 'idiopathic' interstitial lung diseases, cryptogenic organizing pneumonia may also be diagnosed since the amount of bronchial tissue in our subpleural biopsies was sufficient [27]. The existence of polypoid proliferation, involving both the bronchioles and alveolar ducts (organizing pneumonia), is characteristic of organizing pneumonia [27], which might also be present in other 'idiopathic' entities such as nonspecific interstitial pneumonia [22]. In patients with interstitial lung disease, Vansteenkiste et al. [3] performed medical thoracoscopy in 24 patients to evaluate the quality of parenchymal biopsies using neuroleptic anesthesia with spontaneous ventilation. The authors reported very good results in the 118 specimens taken from their patients, with a mean number of biopsies of 6.5 per patient (ranging from 3 to 10), and a good quality of the biopsies in $78 \%$ of the samples. With respect to the classification of interstitial lung diseases available at the time, they were able to differentiate patients having cryptogenic organizing pneumonia (1 patient), UIP (5 patients), desquamative interstitial pneumonia (2 patients), and lymphocytic interstitial pneumonia (2 patients) [3].

In our study, histological examination revealed that vessels were sufficiently present in subpleural specimens. It has previously been reported that suspected pulmonary vasculitis or other pulmonary vascular disorders are poor indications for medical thoracoscopic lung biopsy as its diagnostic yield is poor $[3,4]$. In agreement with other authors [3], our study suggests that this technique could still be considered in the case of suspected vascular pathology, especially if there are lesions in the smaller pulmonary arterioles. Furthermore, the significant pres- 
ence of vessels in our subpleural biopsies gave us the opportunity to study the vascular remodeling phenomenon observed in the disease, which has been reported to be present in patients with idiopathic pulmonary fibrosis by CD34- immunostaining [22, 28].

In conclusion, subpleural biopsies by the pleuroscopic route provided satisfactory material for histologic examination and the quality of those biopsies was similar to that of deep lung biopsy specimens obtained by electrocautery in animal subjects. Therefore, in DPLD, where the subpleural layers are involved, this method might be conducive to an accurate diagnosis. The present study could form the basis of further clinical studies specifically addressing the role of lung biopsies obtained via medical pleuroscopy in DPLD.

\section{References}

1 Rodriguez-Panadero F: Medical thoracosco- 11 Qureshi RA, Ahmed TA, Grayson AD, py. Respiration 2008;76:363-372.

$>2$ Froudarakis ME: Diagnostic work-up of pleural effusions. Respiration 2008;75:4-13.

$>3$ Vansteenkiste J, Verbeken E, Thomeer M, Van Haecke P, Eeckhout AV, Demedts M: Medical thoracoscopic lung biopsy in interstitial lung disease: a prospective study of biopsy quality. Eur Respir J 1999;14:585-590.

$\checkmark 4$ Dijkman JH, van der Meer JW, Bakker W, Wever AM, van der Broek PJ: Transpleural lung biopsy by the thoracoscopic route in patients with diffuse interstitial pulmonary disease. Chest 1982;82:76-83.

$\checkmark 5$ Miller JD, Urschel JD, Cox G, Olak J, Young JE, Kay JM, et al: A randomized, controlled trial comparing thoracoscopy and limited thoracotomy for lung biopsy in interstitial lung disease. Ann Thorac Surg 2000;70: 1647-1650.

6 Allen MS, Deschamps C, Jones DM, Trastek VF, Pairolero PC: Video-assisted thoracic surgical procedures: the Mayo experience. Mayo Clin Proc 1996;71:351-359.

7 American Thoracic Society/European Respiratory Society International Multidisciplinary Consensus. Classification of the Idiopathic Interstitial Pneumonias Am J Respir Crit Care Med 2002;165:277-304.

$>8$ Utz P, Ryu JH, Douglas WW, Hartman TE, Tazelaar HD, Myers JL, Allen MS, Schroeder DR: High short-term mortality following lung biopsy for usual interstitial pneumonia. Eur Respir J 2001;17:175-179.

$\checkmark 9$ Maldonado F, Ryu JH: Surgical biopsy for diffuse parenchymal lung diseases: are we causing more harm than good? J Bronchol Intervent Pulmonol 2009;16:227-228.

-10 Kreider ME, Hansen-Flaschen J, Ahmad NN, Rossman MD, Kaiser LR, Kucharczuk JC, et al: Complications of video-assisted thoracoscopic lung biopsy in patients with interstitial lung disease. Ann Thorac Surg 2007;83:1140-1144.
Soorae AS, Drakeley MJ, Page RD: Does lung biopsy help patients with interstitial lung disease? Eur J Cardiothorac Surg 2002;21: 621-626; discussion 626.

12 Van Schil P: Cost analysis of video-assisted thoracic surgery versus thoracotomy: critical review. Eur Respir J 2003;22:735-738.

13 England GC, Clarke KW: The use of medetomidine/fentanyl combinations in dogs. Acta Vet Scand Suppl 1989;85:179-186.

14 Robinson EP, Sams RA, Muir WW: Barbiturate anesthesia in greyhound and mixedbreed dogs: comparative cardiopulmonary effects, anesthetic effects, and recovery rates. Am J Vet Res 1986;47:2105-2112.

15 Boutin C, Viallat JR, Cargnino P, Rey F: Thoracoscopic lung biopsy. Experimental and clinical preliminary study. Chest 1982;82: 44-48.

16 Colt HG, Russack V, Shanks TG, Moser KM: Comparison of wedge to forceps videothoracoscopic lung biopsy. Gross and histologic findings. Chest 1995; 107:546-550.

17 Zompatori M, Bna C, Poletti V, Spaggiari E, Ormitti F, Calabro E, Tognini G, Sverzellati $\mathrm{N}$ : Diagnostic imaging of diffuse infiltrative disease of the lung. Respiration 2004;71:419.

18 Poletti V, Chilosi M, Olivieri D: Diagnostic invasive procedures in diffuse infiltrative lung diseases. Respiration 2004;71:107-119.

19 Nagai S, Handa T, Ito Y, Takeuchi M, Izumi $\mathrm{T}$ : Bronchoalveolar lavage in idiopathic interstitial lung diseases. Semin Respir Crit Care Med 2007;28:496-503.

20 Romagnoli M, Bigliazzi C, Casoni G, Chilosi M, Carloni A, Dubini A, et al: The role of transbronchial lung biopsy for the diagnosis of diffuse drug-induced lung disease: a case series of 44 patients. Sarcoidosis Vasc Diffuse Lung Dis 2008;25:36-45.

21 Raghu G: Interstitial lung disease: a diagnostic approach. Are CT scan and lung biopsy indicated in every patient? Am J Respir Crit Care Med 1995;151:909-914.
22 Katzenstein AL, Myers JL: Nonspecific interstitial pneumonia and the other idiopathic interstitial pneumonias: classification and diagnostic criteria. Am J Surg Pathol 2000; 24:1-3.

23 Strieter RM: Pathogenesis and natural history of usual interstitial pneumonia: the whole story or the last chapter of a long novel. Chest 2005; 128(5 suppl 1):526S-532S.

24 Gal AA: Use and abuse of lung biopsy. Adv Anat Pathol 2005;12:195-202.

25 Raghu G, Collard HR, Egan JJ, Martinez FJ, Behr J, Brown KK, Colby TV, Cordier JF, Flaherty KR, Lasky JA, Lynch DA, Ryu JH, Swigris JJ, Wells AU, Ancochea J, Bouros D, Carvalho C, Costabel U, Ebina M, Hansell DM, Johkoh T, Kim DS, King TE Jr, Kondoh Y, Myers J, Muller NL, Nicholson AG, Richeldi L, Selman M, Dudden RF, Griss BS, Protzko SL, Schunemann HJ: An official ATS/ ERS/JRS/ALAT statement: idiopathic pulmonary fibrosis: evidence-based guidelines for diagnosis and management. Am J Respir Crit Care Med 2011;183:788-824.

26 Quadrelli S, Molinari L, Ciallella L, Spina JC, Sobrino E, Chertcoff J: Radiological versus histopathological diagnosis of usual interstitial pneumonia in the clinical practice: does it have any survival difference? Respiration 2010;79:32-37.

27 Colby TV: Bronchiolitis. Pathologic considerations. Am J Clin Pathol 1998;109:101-109.

28 Ebina M, Shimizukawa M, Shibata N, Kimura Y, Suzuki T, Endo M, et al: Heterogeneous increase in CD34-positive alveolar capillaries in idiopathic pulmonary fibrosis. Am J Respir Crit Care Med 2004;169:1203-1208. 